\title{
Using 2-term AVO attributes to validate gas anomalies on Colombian Caribbean offshore
}

Antonio Carlos Lira Pessoa and Elita Selmara de Abreu

Copyright 2019, SBGf - Sociedade Brasileira de Geofísica

This paper was prepared for presentation during the $16^{\text {th }}$ International Congress of the Brazilian Geophysical Society held in Rio de Janeiro, Brazil, 19-22 August 2019.

Contents of this paper were reviewed by the Technical Committee of the $16^{\text {th }}$ International Congress of the Brazilian Geophysical Society and do not necessarily represent any position of the SBGf, its officers or members. Electronic reproduction or storage of any part of this paper for commercial purposes without the written consent of the Brazilian Geophysical Society is prohibited.

\section{Abstract}

This study was part of a post-mortem effort involving wells that showed similar seismic signatures but had very different results. Using rock physics and 1-D AVO modelling, we were able to look into the overpressure effects on reservoir's elastic properties that seem to affect mostly $V_{P}$ and $V_{S}$ rather than density. We show that the use of attributes (A and D), as proposed by Fatti et al. (1994), is more suitable for this kind of circumstances than the more classic AVO approach, based on intercept and gradient (A and B), as in Shuey (1985). This integrated study could not only explain the well results but also provide insights to reduce the exploration risk in the Colombian Caribbean offshore.

\section{Introduction}

Colombian Caribbean offshore exploration started on the early 60's. Since then thirty-nine wells have been drilled with seven dry gas discoveries. Only in 2007 the first deep-water well was drilled, and it confirmed the presence of Miocene and Oligocene sandstones with gas shows. Seven years later, Petrobras, along with Ecopetrol, Repsol and Equinor, made the first deep-water discovery in the Colombian Caribbean basins.

The Tayrona Block is located within the Caribbean deformation belt and covers around $13.000 \mathrm{~km}^{2}$ (figure 1). Its prospects are directly related to the Caribbean Plate oblique tectonics, which forms and deforms traps as it moves eastwards

$\mathrm{DHI}$ (Direct Hydrocarbon Indicator) analysis has been around for many decades in the exploration business. Not surprisingly, since we are dealing with Oligocene reservoirs saturated with gas, it is also a useful tool to derisk the exploration opportunities in this area.

Two wells with strong AVO anomaly and similar seismic signatures (figure 2) were recently drilled in the area. The first well found gas-saturated reservoirs with an AVO class II-III anomaly. The second found no reservoir, resulting in a seismic pit-fall. This unexpected result encouraged a more detailed geophysics study, using local wells, rock physics measurements, seismic processing, and interpretation.

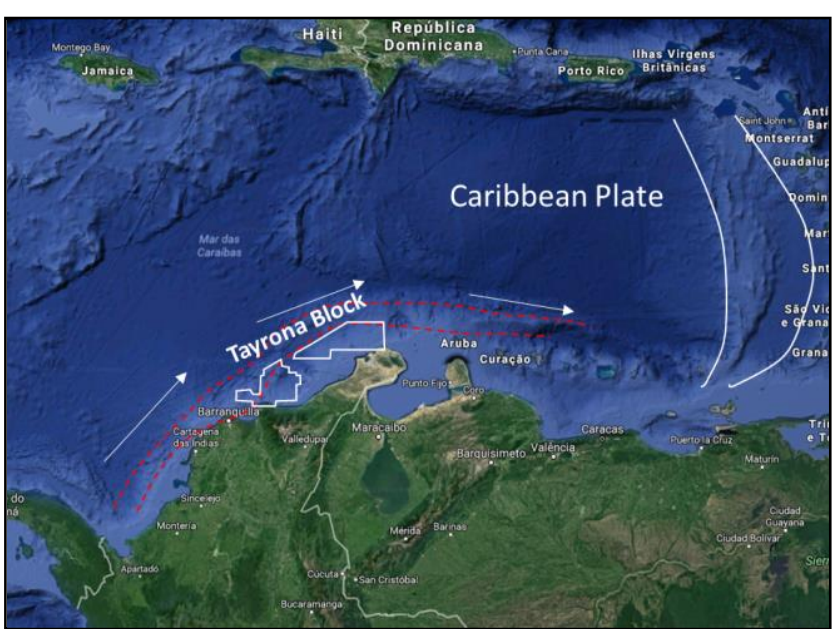

Figure 1 - Location of Tayrona Block in Colombian Caribbean Offshore. Note the strong influence of the Caribbean Plate movement and deformation belt (red dot lines) around the study area. Image: Google Maps

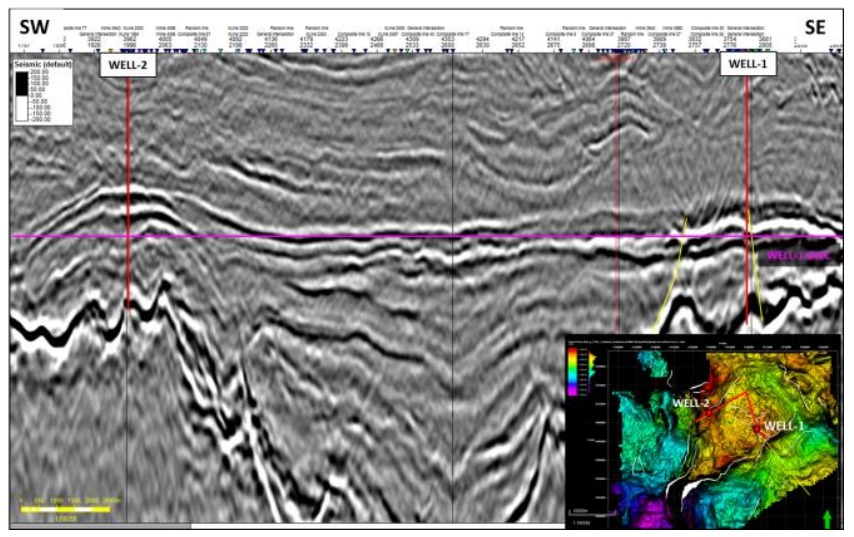

Figure 2 - Arbitrary Kirchhoff PSDM section between the two considered wells, showing the similarity between amplitude anomalies. The purple line indicates the gaswater contact sampled by WELL-1.

\section{Methodology}

In this work, we analyze and compare Fatti et al. and Shuey's approximations for the Zoeppritz equations on partial-stack data, open gathers and 1D well-based AVO modeling. The table below shows a brief comparison of these approximations. 
Table 1 - Comparison between Shuey (1985) and Fatti et al. (1994) aproximations for Zoeppritz equations (modified by Rosa, 2018).

\begin{tabular}{|c|c|}
\hline Shuey (1985) & Fatti et al. (1994) mod. by Rosa (2018) \\
\hline$R(\theta)=A+B \operatorname{sen}^{2} \bar{\theta}+C \operatorname{sen}^{2} \bar{\theta} \tan ^{2} \bar{\theta}$ & $R(\theta)=A\left(1+\tan ^{2} \theta\right)+D \operatorname{sen}^{2} \theta-E \operatorname{sen}^{2} \theta \tan ^{2} \theta$ \\
\hline$A=\frac{1}{2}\left(\frac{\Delta V_{P}}{\overline{V_{P}}}+\frac{\Delta \rho}{\bar{\rho}}\right)=\frac{1}{2} \frac{\Delta I_{P}}{I_{P}}$ & $A=\frac{1}{2}\left(\frac{\Delta V_{P}}{\overline{V_{P}}}+\frac{\Delta \rho}{\bar{\rho}}\right)=\frac{1}{2} \frac{\Delta I_{P}}{I_{P}}$ \\
\hline $\mathrm{B}=-k A+(1-k) C+\frac{\Delta \sigma}{(1-\bar{\sigma})^{2}}$ & $\mathrm{D}=(k-1) E-k \frac{\Delta I_{S}}{I_{S}}$ \\
\hline$C=\frac{1}{2}\left(\frac{\Delta V_{P}}{\overline{V_{P}}}\right)$ & $E=\frac{1}{2}\left(\frac{\Delta \rho}{\bar{\rho}}\right)$ \\
\hline$k=4 \frac{{\overline{V_{S}}}^{2}}{{\overline{V_{P}}}^{2}}$ & $k=4 \frac{{\overline{V_{S}}}^{2}}{{\overline{V_{P}}}^{2}}$ \\
\hline \multicolumn{2}{|c|}{ Assumptions and Limitations } \\
\hline $\begin{array}{l}\text { - Rearranges Aki \& Richards } \\
\text { aproximation as a function of the } \\
\text { range of angles. } \\
\text { - Valid for typical contrast of elastic } \\
\text { properties. } \\
\text { - A is related to P impedance while B } \\
\text { term is related to Poisson's Ratio. }\end{array}$ & $\begin{array}{l}\text { - Makes no assumption for elastic properties } \\
\text { variations. } \\
\text { - The parameter } A \text { is related to } P \text { impedance while } \\
\text { D is related to } S \text { impedance. } \\
\text { - } B \text { (or gradient) is equivalent to } A+D \text {. }\end{array}$ \\
\hline
\end{tabular}

The third terms $\mathrm{C}$ and $\mathrm{E}$ in both approximations are weighted by the factor $\operatorname{sen}^{2}(\theta) \tan ^{2}(\theta)$, as seen in Table-1, which makes them more important as incidence angles increase. As the incidence angles of the acquired seismic data are smaller than $30^{\circ}$, we limited our analyzes to the 2-term approximations and considered the factor $\mathrm{k}$ to be equal to 1 (or $V_{P} / V_{S}=2$ ), a common assumption in AVO works, as in Verm \& Hilterman (1995). One important point is that $\mathrm{C}$ is a function of $\mathrm{V}_{\mathrm{P}}$ while $\mathrm{E}$ is a function of $\rho$. Since $V_{P}$ contrasts are more important than density ones, as can be demonstrated through Gardner's empirical relation, the 2-term Fatti et al. approximation is a better way to truncate the third term than the equivalent Shuey one. In this way, the 2-terms Fatti et al. approximation is more suitable to describe the dependence of the reflection coefficients $\mathrm{R}$ with the incidence angle $\theta$, for angles smaller than $30^{\circ}$, especially when strong $V_{P}$ contrasts are present.

As part of this work, the seismic data was reprocessed in order to generate $A$ and $D$ attributes from pre-stack gathers. Elastic properties were measured and analyzed in core samples of the reservoir under in situ conditions to generate an estimated $V_{S}$ curve, since it was only acquired in WELL-1.

\section{Results}

WELL-2 is located in an overpressured zone (high porepressure), which implies decreases of $\mathrm{V}_{\mathrm{P}}$ and $\mathrm{V}_{\mathrm{S}}$, but not of density in this area. This behavior can be seen in figure 3 , where $V_{\mathrm{P}}, \mathrm{V}_{\mathrm{S}}$ and density curves are plotted versus the burial depth for five wells: three of them under normal pressure conditions (WELL-3, WELL-4 and WELL-5) and two under overpressure conditions (WELL-1 and WELL2).

The rock physics analysis for the samples of WELL-2 (figure 4) also brought some key insights about the behavior of $V_{P}, V_{S}$ and density: they do not follow the empiric Gardner's equation or the Mudrock Line (Castagna et al. 1985). After adjusting the curves and calculating a new $V_{S}$ log for WELL-2, we performed 1-D AVO modelling to look into the differences between the compared techniques using well data.

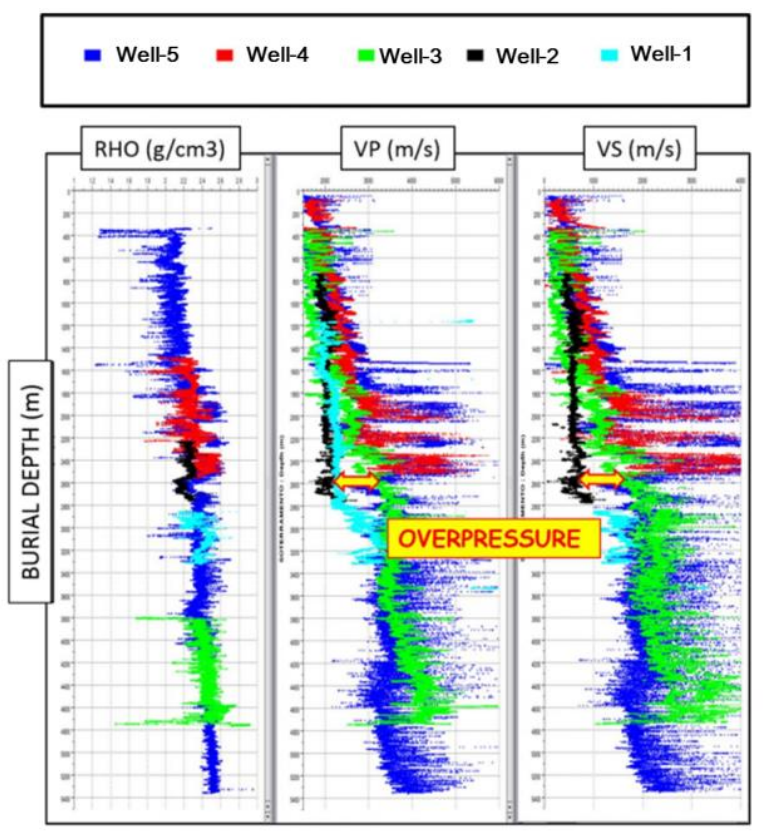

Figure 3 - Variation of elastic properties with burial depth for the wells WELL-5 (blue), WELL-4 (red), WELL-3 (green), WELL-2 (black), WELL-1 (cyan). The density variation (left) looks the same for all the wells, while $V_{P}$ (center) and $\mathrm{V}_{\mathrm{S}}$ (right) show lower values for the overpressured wells (WELL-1 and WELL-2).

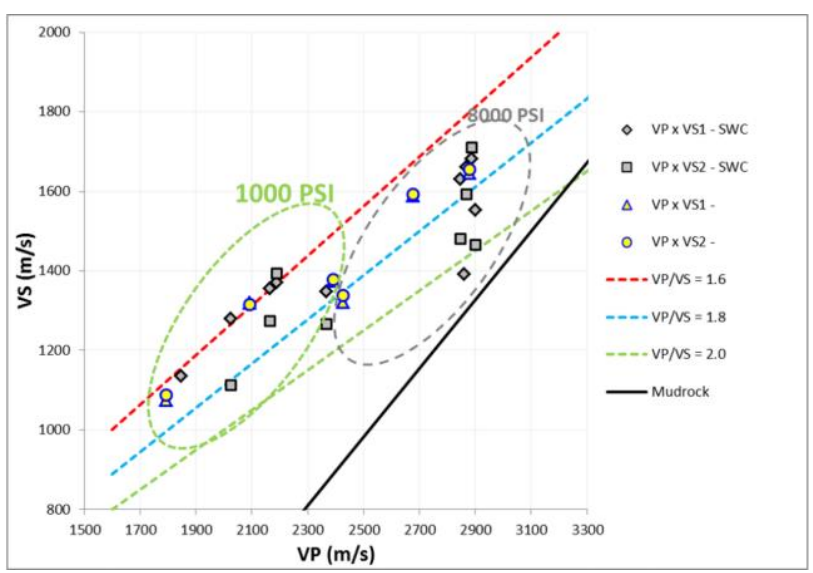

Figure 4 - Graphic of $V_{P}$ versus $V_{S}$ of the side-wall samples measured at CENPES Rock Physics laboratory. Samples (gray squares) and sub-samples (green circle) measurements are plotted for the confining pressures of 1000 psi (gray dotted circle) and 8000-psi (gray dotted circle). Note that the samples do not follow the Mudrock line and follow above it. The doted lines represent different $V_{P}-V_{S}$ ratio values for the sample measurements (red 1.6; blue 1.8; green 2.0), while the black line is the Mudrock Line.

To address this anomalous behavior, especially with respect to $V_{P}$ and $V_{S}$, 2-term Fatti et al. approximation 
seems much more suitable than the equivalent Shuey's one, since we are dealing with significative $V_{P}$ and $V_{S}$ changes.

Figure 5 compares both modellings with the $V_{S}$ curve calculated directly from WELL-1 $V_{P}-V_{S}$ relationship (scenario a) and the one adjusted after $\mathrm{V}_{\mathrm{P}}-\mathrm{V}_{\mathrm{S}}$ relationship measured on the core samples (scenario b). The first important aspect is that Poisson's ratio at the reservoir is very different for each scenario. In scenario a the Poisson' $s$ ratio is slightly higher than the expected trend, while in scenario $b$ the Poisson's ratio shows much lower values. In scenario $b$, the modelling, as expected, has shown that for the pit-fall situation (absence of reservoir), the attribute $2 A+D$ from Fatti et al. is not anomalous while the attribute $A+B$ from Shuey is. This is a clear evidence that this technique is less likely to induce $A V O$ misinterpretation. In scenario $a$, both $2 A+D$ and $A+B$ show very similar responses. In other words, if the reservoir followed Gardner and the Mudrock equations, $2 A+D$ and $A+B$ would be equivalent, as the empiric elastic contrasts would not be significant enough to differ the two methods and $R(\theta)$ would be approximately linear with $\operatorname{sen}^{2}(\theta)$.

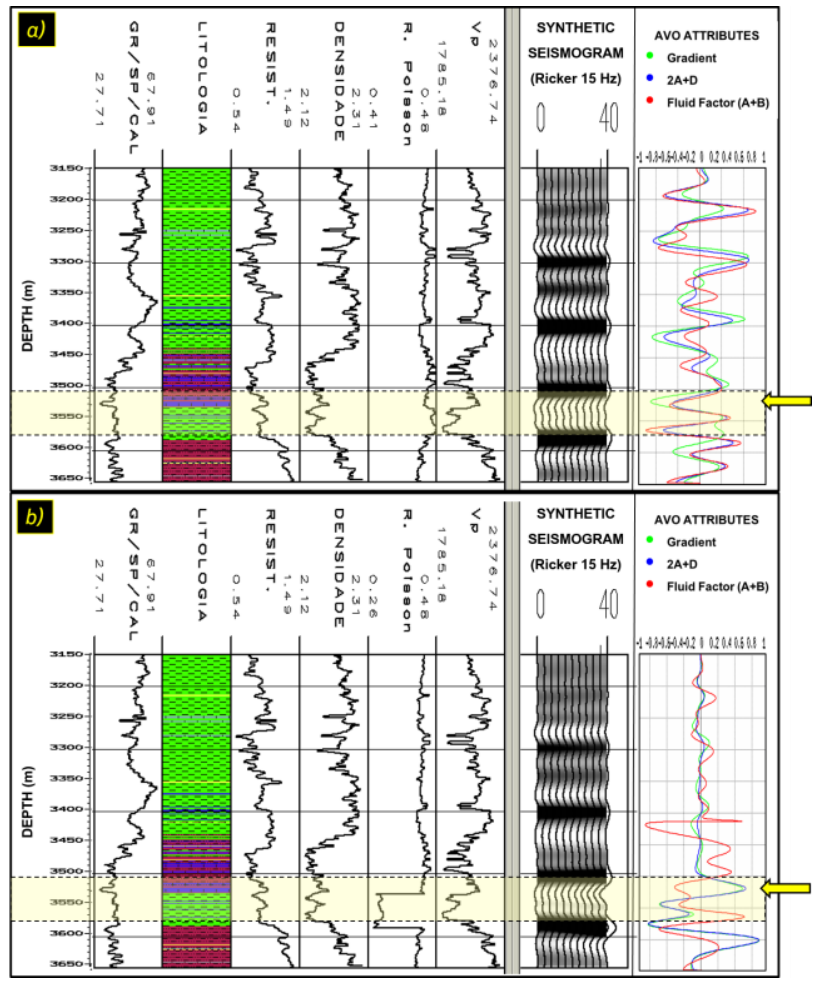

Figure 5 - Comparison of the AVO modeling for WELL-2 reservoir a) $V_{s}$ calculated based on WELL-1, which was the expected scenario prior to drilling; and b) $\mathrm{V}_{\mathrm{s}}$ calculated based on lab measurements, which is the verified scenario after drilling. Note that on the expected scenarios all attributes (Gradient, $2 A+D$, and Fluid Factor $(\sim A+B)$ ), shows similar response exhibiting an anomalous behavior at the top of the reservoir (yellow arrow); while in the drilled scenario, only the Fluid Factor shows an anomalous response.
The next step was to see if all this study could actually be applied into seismic volumes and help de-risk future $\mathrm{DHI}$ prospects in the area. Our seismic processing team calculated $A$ and $B$, as well as $A$ and $D$ attributes from pre-stack data, using the considered approximations, thus both seismic sections and amplitude maps could be compared (figure 6).

The comparison between the maps generated by both methods shows notable differences for the pitfall anomaly around WELL-2. According to these maps we can conclude that the Fatti et al. DHI map is able to distinguish the pitfall anomaly from the one caused by the presence of gas, which is in agreement with the well based AVO modeling. This result is also illustrated in Figure 7, which shows a seismic section through these wells for the Fatti et al. $2 A+D$ attribute. In the figure, the gas anomaly sampled by WELL- 1 is more evident than the pitfall one sampled by WELL-2.

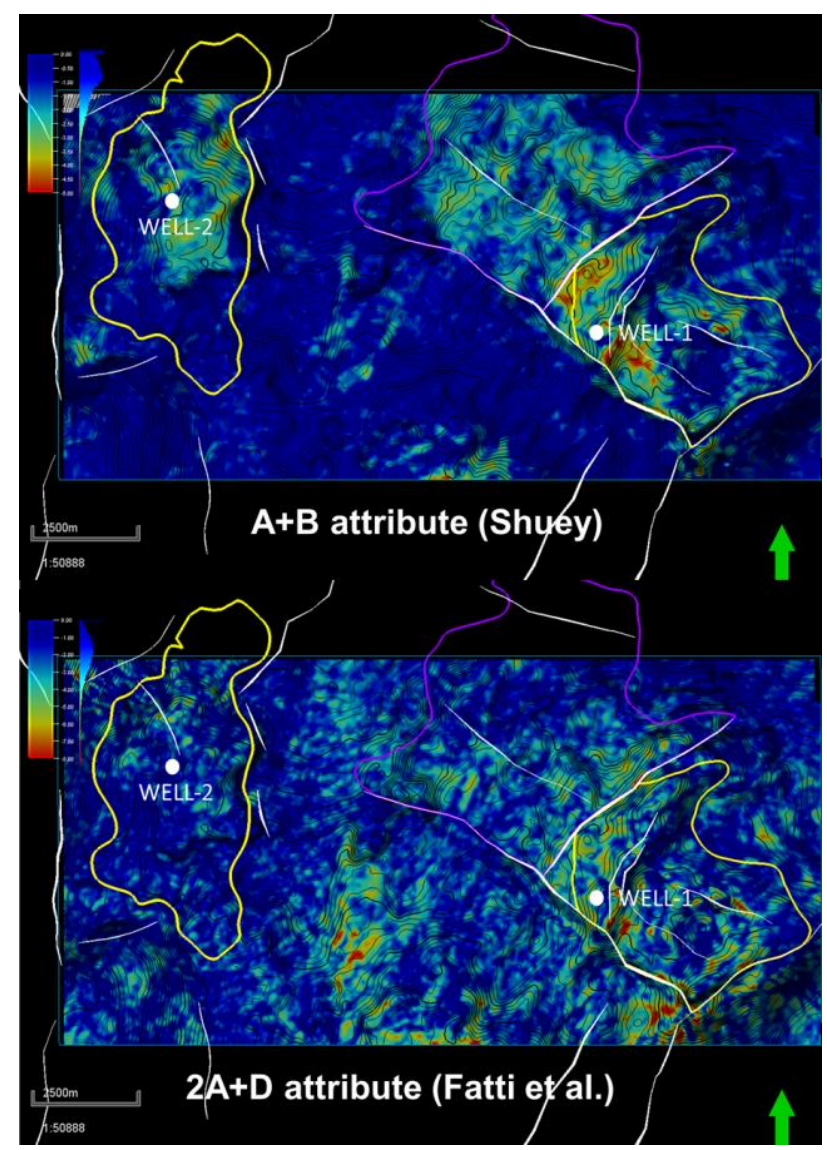

Figure 6 - Comparison of Shuey and Fatti et al. 2-terms AVO attributes. Above DHI Attribute based on Intercept and Gradient $(A+B)$ (Shuey, 1985); below DHI Attribute $(2 A+D)$ (Fatti et al., 1994). The comparison between these maps shows that, even though the gas anomaly sampled by WELL-1 is present in both maps, the pit-fall region, around WELL-2, occurs only in the Shuey attribute map. The yellow line highlights the GWC (gas-water contact). 


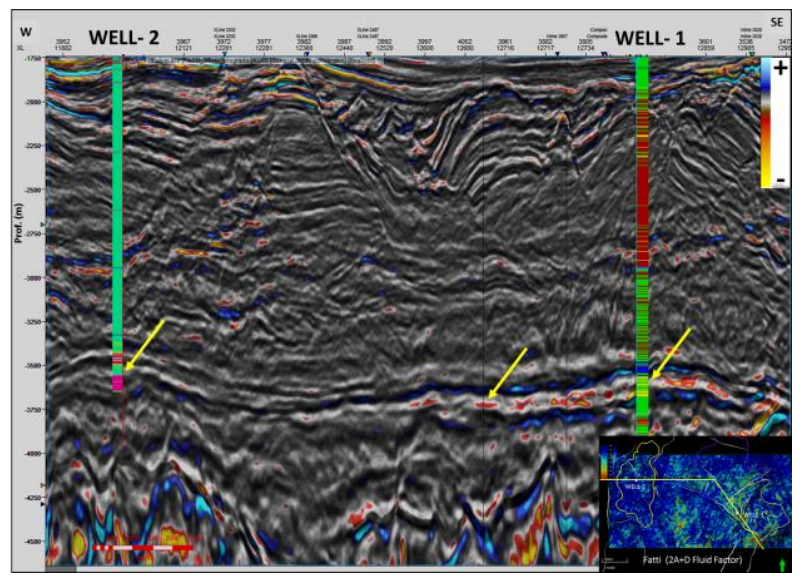

Figure 7: Arbitrary seismic line between WELL-2 (left) and WELL-1 (right) for the $\mathrm{DHI}$ attribute $2 \mathrm{~A}+\mathrm{D}$ derived from Fatti et al. approximation. The gas anomalies are highlighted by the hot colors (red and yellow), which means negative values. Note that, only WELL-1 shows high negative values. In other words, the attribute seems to differentiate the gas accumulation anomaly from the pitfall one.

\section{Conclusions}

This geophysical post-mortem study improved our understanding of the $\mathrm{DHI}$ in the Tayrona Block area. Through this study, we were able to address the risk of lithological pitfall due to overpressure effects and find a better attribute to de-risk it. Measurements of elastic parameters in laboratory were key to understand the rock behavior and calibrate curves to estimate a realistic $V_{S}$ log for WELL-2. The 1-D AVO modeling, based on this estimate, allowed testing AVO attributes of different approximations and their applications in the seismic scale. The use of 2-term Fatti et al. approximation has shown to be more robust for $\mathrm{DHI}$ analysis in overpressure areas, which are usually related to significant velocity contrasts, since it could discriminate the pit-fall from the gas anomaly as opposed to the more traditional Shuey's approximation, where both presented similar AVO responses.

\section{Acknowledgments}

We would like to kindly thank our partners Ecopetrol, Repsol and Equinor for the great teamwork and encouragement that led us to reach an excellent level of maturity and knowledge in Tayrona Project.

We would also like to thank Petrobras seismic processing, seismic interpretation colleagues and to the CENPES rock-physics team that contributed a great deal to this study. A special gratitude to Carlos Lopo Varela for constant consultancy and review of this work.

\section{References}

Aki, K., e P.G. Richards, 1980, Quantitative seismology: Theory and methods: The Freeman, 2002, Quantitative seismology, second edition: University Science Books.

Castagna et al., 1985, Relationships between compressional-wave and shear-wave velocities in elastic silicate rocks. Geophysics vol. 50, No. 4 (April, 1985)

Chopra, S. and J.P. Castagna, 2014, AVO: Investigations in geophysics no. 16, Society of Exploration Geophysicists - SEG.

Fatti et al., 1994, Detection of gas in sandstone reservoirs using AVO analysis: A 3-D seismic case history using de Geostack technique: Geophysics, 59, no. 9, 1362-1376, https:doi.org/10.1190/1.1443695.

Mavko, G., T. Mukerji, and J. Dvorkin, 2003, The rock physics handbook: Tools for seismic analysis in porous media, Cambridge University Press.

Morschbacher, M.J., J.C.R. Justen, and G.F. Vasquez, 2018, Análise Petrossísmica de Amostras Laterais (SWC) do Poço BRAMA-1 (PAD Orca, Colômbia), CENPES/PDEP/IRPS - internal report.

Pessoa, A.C.L., et al., 2018, Atributos A e D de Fatti para o reconhecimento de anomalias de gás no Oligoceno do offshore do Caribe, XI SINTEX - Seminário de Interpretação Exploratória (internal workshop presentation).

Rosa, A.L.R., 2018, Análise do sinal sísmico, 2nd edition, Sociedade Brasileira de Geofísica - SBGf.

Shuey, R. T. 1985, A simplification of Zoeppritz equations: Geophysics, 50, no. 4, 609-614, https://doi.org/10.1190/1.1441936.

Verm, R., and F. J. Hilterman, 1995, Lithology colorcoded seismic sections: The calibration of AVO crossplotting to rock properties. The Leading Edge, 14, no 8, 847-853. Society of Exploration Geophysicists. 